\title{
Carcinoma ex Pleomorphic Adenoma
}

National Cancer Institute

\section{Source}

National Cancer Institute. Carcinoma ex Pleomorphic Adenoma. NCI Thesaurus. Code C4397.

A carcinoma arising in a pre-existing pleomorphic adenoma. It most often occurs in the parotid gland and less often in the submandibular gland and minor salivary gland. Patients usually present with a history of a long-standing mass which recently had undergone rapid growth. The prognosis depends on the invasiveness of the malignant component. Patients with non-invasive or minimally invasive tumors usually have a good prognosis following surgical resection. Invasive tumors are usually aggressive and are associated with recurrences and metastases. 